\title{
Smoking, use of moist snuff and risk of celiac disease: a prospective study
}

Jonas F Ludvigsson ${ }^{1,2^{*}}$, Caroline Nordenvall ${ }^{3}$ and Bengt Järvholm ${ }^{4}$

\begin{abstract}
Background: Smoking status has been linked to several chronic inflammatory conditions but earlier research on smoking and celiac disease (CD) is contradictive. There are little data on moist snuff use and CD. The purpose of this study was to investigate the association between smoking, moist snuff use and later CD.

Methods: We identified individuals with biopsy-verified CD (villous atrophy, histopathology stage Marsh III) through biopsy-reports from Sweden's 28 pathology departments. Data on smoking and moist snuff were collected from the Swedish construction worker database "Bygghälsan" that includes preventive health care check-up data. Through poisson regression we calculated relative risks (RRs) for later CD according to smoking status $(n=305,722)$, and moist snuff status $(n=199,200)$ adjusting for age, sex and decade.
\end{abstract}

Results: During follow-up 488 individuals with smoking data, and 310 with moist snuff data had a diagnosis of CD. The risk of CD was independent of smoking status with all RRs being statistically insignificant and ranging between 0.9 and 1.0. Compared to non-smokers, neither current smokers $(\mathrm{RR}=0.93 ; 95 \% \mathrm{Cl}=0.76-1.14$ ) nor ex-smokers $(\mathrm{RR}=0.98 ; 95 \% \mathrm{Cl}=0.75-1.28)$ were at increased or decreased risk of $\mathrm{CD}$. Risk estimates were similar in moderate smokers ( $R R=0.92 ; 0.72-1.16)$ and heavy smokers ( $R R=0.95 ; 0.74-1.24)$, and did not change when we examined the risk more than ten years after health examination (RR-moderate: 0.90; and RR-heavy: 0.95; both $p>0.05$ ). Moist snuff use was not associated with later $C D(R R=1.00 ; 0.78-1.28)$, or with $C D$ after more than ten years of follow-up ( $R R=1.05 ;$ 0.80-1.38).

Conclusions: We found no association between smoking, moist snuff use and future CD.

Keywords: Autoimmune, Coeliac, Gluten, Smoking, Moist snuff, Snus

\section{Background}

Celiac disease (CD) is characterized by small intestinal inflammation and is triggered by gluten exposure in genetically sensitive individuals [1]. CD occurs in $1-2 \%$ of the Western population $[2,3]$, and has been linked to a number of disorders including type 1 diabetes [4], sepsis [5], lymphoproliferative malignancy [6], and excess mortality [7].

Although almost all individuals with $\mathrm{CD}$ are $\mathrm{DQ} 2+$ or $\mathrm{DQ} 8+$, genetic factors alone cannot explain the risk of CD [8]. Several environmental factors have therefore been put forward as explanations for CD (short breastfeeding [9], and to a lesser extent early infections $[10,11]$ and elective

\footnotetext{
* Correspondence: jonasludvigsson@yahoo.com

'Department of Medical Epidemiology and Biostatistics, Karolinska Institutet, Stockholm 171 77, Sweden

2Department of Paediatrics, Örebro University Hospital, Örebro University, Örebro, Sweden

Full list of author information is available at the end of the article
}

caesarean section [12]), and stressful life events (such as pregnancy, death of relatives or surgery etc $[13,14]$.

Most environmental risk factors have however only been studied in patients with childhood CD, and there is a lack of knowledge about CD risk factors in adults.

Smoking has been linked to a number of inflammatory disorders [15] including Crohn's disease [16], and for a number of gastrointestinal disorders the association seems to be protective (e.g. ulcerative colitis [17] and sclerosing cholangitis [18]). Most earlier studies have shown an inverse relationship also between CD and smoking [19-24], but there are exceptions $[25,26]$. The largest study to date reported a positive association between smoking and $C D$ [26] (Figure 1).

Smokeless tobacco (moist snuff) contains nicotine, which may influence the degree of intestinal inflammation. Moist snuff use in pregnant women has recently 


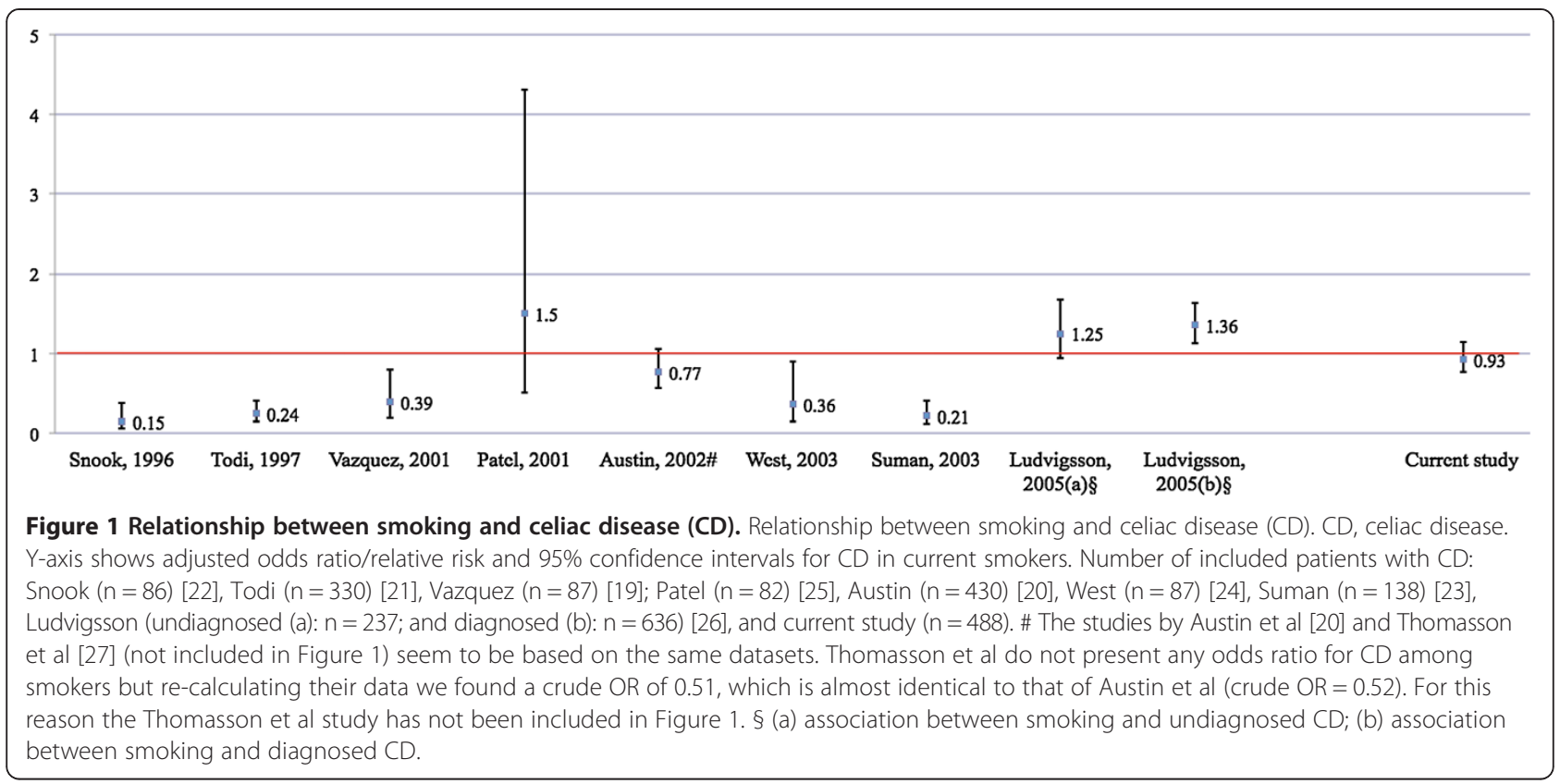

been linked to stillbirth risk [28], and older data suggest a positive association with inflammatory bowel disease [29]. We are unaware of any studies examining its association with $\mathrm{CD}$.

In the current prospective study, we investigated the risk of $\mathrm{CD}$ among smokers and moist snuff users. Smoking and moist snuff are also contrasted as a means to disentangle the potential effect of nicotine exposure (occurs in both) on $\mathrm{CD}$ as opposed to effects of substances that only occur in tobacco smoke.

\section{Methods}

Through the personal identity number [30] we linked data on smoking and moist snuff use obtained from some Swedish construction workers [31,32], with data on CD from Sweden's 28 pathology departments [33].

\section{Smoking and moist snuff use}

Between 1971 and 1993, results from health examinations of white- and blue-collar workers in the Swedish construction industry were computerized. The workers were offered preventive health check-ups by a national occupational health service, "Bygghälsan". Data on health and exposures were collected through questionnaire, and a face-to-face interview by dedicated nurses. During 197577 no tobacco data were collected.

We categorized smoking into three groups (never, former, or current), and then subdivided current into moderate ( $\leq 14$ cigarettes per day or equivalent), and heavy smokers ( $\geq 15$ cigarettes per day). Moist snuff was divided into "ever" and "never users" for those with information after 1978. For the period 1971-74 only current snuff users were included as the variable for non-current users also included those who had not answered. Therefore, the analysis of moist snuff users was based on 199,185 persons (82,572 ever and 116,613 never users). Less than $10 \%$ of the ever-users reported that they had stopped using moist snuff. The quality of smoking data has been reviewed by Engholm et al and is high [34]. A previous review of smoking data at the first and second health examination (2-3 years apart) among 18,593 subjects in the "Bygghälsan" cohort found a $89 \%$ perfect match with data [35]. Inconsistencies regarding never-smoking status (study participants first indicated that they were current/former smokers in one questionnaire and then reported never-smoking in the second questionnaire) were reported for $2.7 \%$ [35].

The original cohort consisted of 389,132 individuals, 369,174 men and 19,418 women. Of those, 15 individuals were excluded because they had a diagnosis of $C D$ before health examination. The mean year of birth in the remaining cohort was 1944 (range 1891-1976), mean year of first examination 1978.8 and mean age at first examination 34.6 years (range $14-82$ years).

The number of recorded health examinations ranged from 1 to 15 , with an average of 3 . In this study we consistently used information on smoking and moist snuff from the first recorded visit (also defined as start of follow-up). There was information on tobacco smoking for 305,722 persons $(290,449$ men and 15,273 women). Information on moist snuff was available for 199,185 persons (187,338 men and 11,847 women).

Details of ethics approval: The study was approved by the Regional ethical review board in Umeå, 2013/225-31. 


\section{Outcome measure: celiac disease}

Between October 2006 and February 2008, we contacted all 28 Swedish pathology departments and obtained biopsy report data on duodenal and jejunal biopsies carried out in 1969-2008. IT personnel retrieved local data on date of biopsy, topography (duodenum or jejunum), morphology codes consistent with villous atrophy (histopathology stage Marsh III; see earlier paper for details [33]), as well as personal identity number [30]. Biopsy reports were on average based on 3 tissue specimen [36]. In this paper villous atrophy equals CD.

After removal of data irregularities, we had information on 29,148 individuals with CD [33]. After excluding two individuals with potentially incorrect date of birth, there remained 29,146 individuals. CD was the outcome measure of our study.

\section{Statistics}

Person-years of follow up were calculated for each person from year of health examination within the construction worker service through 31 December 2008, CD, death or emigration, whichever occurred first. The person-years were stratified for age (10-year age-classes), decennium, sex and tobacco smoking or use of moist snuff.

In a post-hoc analysis we stratified for sex of the participants.

Relative risks were estimated from Poisson regression analysis. 95\% confidence intervals were calculated by Wald estimates.

We used statistics software SAS 9.3 to calculate statistics. P-values $<0.05$ were considered statistically significant.

A post-hoc power calculation (assuming a baseline prevalence of $0.16 \%$ for diagnosed $C D$ among non-smokers) showed that we had an $80 \%$ power at 5\% significance level to detect either a $29 \%$ increased risk or a $23 \%$ decreased risk of $\mathrm{CD}$ among smokers.

\section{Ethics}

This study was approved by the Regional Ethical Review Board in Umeå (2013/225-31).

\section{Results}

In the cohort of construction workers we identified 656 individuals $(0.2 \%)$ with a biopsy-verified diagnosis of $\mathrm{CD}$, 597 men and 59 women. They were on average 54.8 years old at time of diagnosis and the time between diagnosis and first health examination at "Bygghälsan" was 19.6 years (range 0-35 years). Of these 488 had available data on smoking status and 310 had data on moist snuff.

\section{Smoking and CD}

The cases with $\mathrm{CD}$ in the cohort had similar distribution of smoking habits as the total cohort, (Table 1). The risk of $\mathrm{CD}$ was independent of smoking status (and time
Table 1 Smoking habits in the cohort $(\mathrm{N}=305,722$ and cases with $C D(N=488)$

\begin{tabular}{lll}
\hline Smoking habits & $\begin{array}{l}\text { Total cohort } \\
(\%)\end{array}$ & $\begin{array}{l}\text { CD cases } \\
\text { (\%) }\end{array}$ \\
\hline Non-smokers & 43.6 & 44.7 \\
Ex-smokers & 15.1 & 16.1 \\
Moderate smokers & 24.2 & 22.5 \\
Heavy smokers & 17.1 & 16.7 \\
\hline
\end{tabular}

since health check-up) with all RRs being statistically insignificant and ranging between 0.9 and 1.0 (Table 2). Adjusted risk estimates were similar in moderate smokers $(\mathrm{RR}=0.92 ; 95 \% \mathrm{CI}=0.72-1.16)$ and heavy smokers $(\mathrm{RR}=$ $0.95 ; 0.74-1.24)$, and did not change when we examined the risk more than ten years after health examination (RR-moderate: 0.90; and RR-heavy: 0.95; both $\mathrm{p}>0.05$ ) (Table 2). As some other studies have estimates for current smokers we have also calculated risk estimates for the combined group of moderate and heavy smokers ( 0 years after examination $\mathrm{RR}=0.93$; $95 \% \mathrm{CI} \quad 0.76-1.14$ and 10 years after examination $R R=0.92$; 95\% CI. 0.74-1.15).

\section{Moist snuff use and CD}

Moist snuff use was not associated with $C D(R R=1.00$; 0.78-1.28). When restricting our analysis to follow-up after more than ten years after the health examination, the adjusted $\mathrm{RR}$ was 1.05 (95\% $\mathrm{CI}=0.80-1.38)$.

\section{Tobacco smoking and use of moist snuff and CD}

We also compared the risk of $\mathrm{CD}$ in those who both smoked and used moist snuff compared with no use of tobacco products. The analysis was restricted to men with data on both smoking habits and use of moist snuff

Table 2 Relative risk of CD according to smoking status

\begin{tabular}{|c|c|c|}
\hline \multicolumn{3}{|l|}{ Smoking status } \\
\hline & $\mathrm{RR}^{\#}$ & $95 \% \mathrm{Cl}^{\S}$ \\
\hline \multicolumn{3}{|l|}{ Latency $>=0$ years $*$} \\
\hline Non-smokers & 1.00 & \\
\hline Ex-smokers & 0.98 & $0.75-1.28$ \\
\hline Moderate smokers & 0.92 & $0.72-1.16$ \\
\hline Heavy smokers & 0.95 & $0.74-1.24$ \\
\hline \multicolumn{3}{|l|}{ Latency $>=10$ years $*$} \\
\hline Non-smokers & 1.00 & \\
\hline Ex-smokers & 0.99 & $0.75-1.31$ \\
\hline Moderate smokers & 0.90 & $0.70-1.16$ \\
\hline Heavy smokers & 0.95 & $0.72-1.27$ \\
\hline
\end{tabular}

$\mathrm{RR}$, Relative risk adjusted for age, sex and decade.

1.00 constitutes reference.

${ }^{*} \geq$ years since health examination where the smoking habits were decided.

"Poisson regression analysis (age in 10-year-intervals).

${ }^{5}$ Wald estimates. 
$(\mathrm{N}=230,151)$ and showed no significant association between use of tobacco and never using moist snuff or smoking $(R R=0.91 ; 0.69-1.19)$.

\section{Posthoc analyses stratified for sex}

A posthoc analysis restricted to only women showed an inverse risk with smoking (RR for current smokers 0.46 (0.22-0.96). An analysis restricted to only men showed no association with smoking (current smokers RR 0.98 95\% CI 0.79-1.21).

\section{Discussion}

This prospective cohort study found no association between smoking, moist snuff use and CD. In fact almost all RRs were between 0.9 and 1.0. Relative risks for future $\mathrm{CD}$ did not change when we required a 10 -yearlatency from health examination (with smoking status) and $C D$, and were similar in moderate $(R R=0.92)$ and heavy smokers $(R R=0.95)$. Also the $R R$ s for $C D$ in moist snuff users were around 1 .

As can be seen from Figure 1, most earlier studies have shown an inverse relationship between $C D$ and current smoking (none of them have looked at CD and moist snuff use). The exceptions are our previous study [26] and that of Patel et al. [25]. The current study found no association between $\mathrm{CD}$ and smoking, and shares several traits with our study from 2005 [26]. In both studies were data on smoking collected prospectively and independently of the CD diagnosis. The two studies are also the biggest so far (see legend, Figure 1) resulting in high study power and narrow confidence intervals. The $95 \% \mathrm{CI}$ for CD in current smokers ranged between 0.76 and 1.14 in our present study.

As for ex-smoking and $\mathrm{CD}$, all earlier studies have shown higher ORs than for current smoking $(\mathrm{OR}=0.52$ [23], 0.71 [24], 0.99 [20]; and in an Argentinean study the negative relationship with current smoking $(\mathrm{OR}=$ 0.39) even turned into a positive one for ex-smoking $(\mathrm{OR}=1.46)[19])$. The OR for ex-smoking and $\mathrm{CD}$ was almost identical to that of current smoking in the study from the Mayo clinic by Patel et al (1.6 [25]), and similarly in the current study where the ex-smoking $R R$ was absolutely neutral (0.98).

As the collection of data on smoking and moist snuff was prospective and independent of that of $\mathrm{CD}$, we are likely to have eliminated recall bias and selection bias with regards to controls. In contrast, several older studies have drawn controls from inpatients (ear-nose and ortopedics [23]; trauma and orthopedics [22]). This may well overestimate the smoking rate in controls since smokers are at increased risk of both ear-nose disease and fractures; and such controls subsequently underestimate the OR for CD among smokers. There is also a risk that some earlier studies have identified individuals with a more severe $\mathrm{CD}$ than in the average patient with $\mathrm{CD}$ since studies were limited to one (sometimes tertiary) centre $[19,22,23,25]$, and this may bias the RRs in either direction. If the diagnosis of $\mathrm{CD}$ is depending on socioeconomic factors an inverse relation with smoking may occur as persons with low socioeconomic status usually smoke more today and may have lower availability to medical care in some countries. Earlier reports of CD and smoking have however shown that adjustment for socioeconomic status [22,23] rarely influences the risk estimates, and we recently showed that socioeconomic status and education level are only of minor importance for CD rates in Sweden [37]. The lack of association between CD and socioeconomic status in Sweden contrasts with British data, and given that some of the strongest inverse relationships between $C D$ and smoking have been seen in British studies [20,22-24] we cannot rule out that country-specific factors and unidentified confounding have influenced risk estimates in our and earlier studies. This said socioeconomic status is unlikely to influence the current study more than marginally since our study includes workers with similar socioeconomic status for most occupational groups. However, we cannot fully rule out a healthy worker effect. If smoking is primarily associated with severe symptoms (classical CD [38]), and such symptoms prohibit individuals from working we may have underestimated an association (positive or negative) between $\mathrm{CD}$ and smoking.

In the current study, data on smoking were obtained through standardized questionnaires and sometimes with the assistance of nurses. Also earlier studies have used either questionnaires $[20,24,25]$ or personal interviews $[19,23]$ (or a combination $[26,39]$ ) to collect data.

The proportion of current smokers (41\%) in our study was higher than in most earlier studies (proportion among controls: $10 \%$ [25], 13\% [24], 24\% (overall smoking rate [26]), 30\% [23], 33\% [19,20,22], and 42\% [21]) but our rate is nevertheless consistent with Swedish national data from the 1970s-1990s. Of note, a high proportion of smokers will per se not influence RRs, but rather increase study power.

Some $95 \%$ of our study population consisted of males. This contrasts with other studies where women have dominated (females with CD: 56\% [25], 66\% [22,24], 67\% [23], 73\% [20], 83\% [19], 100\% [26]). Still, our study included more than 15,000 females. Females had higher risk of $\mathrm{CD}$ than men. The estimates in our study were otherwise adjusted for sex by a categorical variable. A posthoc analysis restricted to only women showed an inverse risk with smoking (RR for current smokers 0.46, while no inverse relationship was seen in men (current smokers RR 0.98). Women in this cohort include a rather large group of office workers. Analysing women adjusting for being an office worker or not showed a slightly lower 
RR (0.36; 95\% CI 0.14-0.90) and separate analysis for the two groups of women showed similar results $(R R=0.36$ and $\mathrm{RR}=0.36$ ) but with wider confidence limits. Thus, our data indicate that $\mathrm{CD}$ may be inversely associated to smoking in women but not in men. These findings contrast with our earlier study where we saw no relationship between smoking and $\mathrm{CD}$ in a female population [40]. One explanation for the difference between the two studies is that the former [40] was limited to women becoming pregnant (potentially different from the general CD population), but also that the $\mathrm{CD}$ diagnosis in our 2005 paper [40] was based on the inpatient diagnosis of $C D$, rather than biopsy-verified CD (current paper). Interaction between smoking and sex has been seen for other immunemediated diseases such as rheumatoid arthritis [41]. Sex may also influence disease phenotype [42]. If smoking influences age at symptom onset that could also have influenced our findings since the median age at CD diagnosis was almost 55 years in this study, and our pregnancysmoking paper was based on women aged 15-44 years [40], with most women being between 20 and 34 years old.

Finally, our cohort includes rather few women with CD $(n=43)$ and mostly non-smokers $(n=27)$ and fewer current smokers $(n=10)$ and ex-smokers $(n=6)$ so the negative relationship between $\mathrm{CD}$ and smoking may also be a chance finding. It should be stressed that the $95 \%$ CIs overlapped between men and women.

We did not have data on symptoms. We cannot rule out that if an inverse relationship with smoking is restricted to patients with classical [38] symptoms we might have missed it. For instance Snook et al [22] only included patients with diarrhoea and malabsorption. Considering that symptoms in adult CD seems to have changed $[43,44]$, the relevance of studies restricted to patients with malabsorption can be questioned. When we reviewed patient charts from a random subset of individuals CD [33], diarrhoea occurred in 36\% of our celiac patients, this is almost identical to that of patients with CD diagnosed later than year 2000 in a US centre (37\%) [43]. Still we cannot rule out that the composition of celiac cases in our study differs slightly from that of studies where data collection on $\mathrm{CD}$ took place in the 1990s [19,20,23-25] or earlier [22], and that decade may have influenced our risk estimates. In our study, RRs generally increased (became "less inverse") after adjustment for decade (data not shown).

In 2001, Prasad reported that anti-endomysial status may be important to smoking among patients with CD [45]. In their paper, EMA-negative status was strongly associated with smoking $(\mathrm{OR}=7.0)$ [45]. The use of celiac serology to identify individuals with $C D$ has increased greatly in the last 15-20 years, and it is possible that the association between $\mathrm{CD}$ and smoking is less inverse in serology-positive individuals. Results by West et al [24] argue against this as their celiac study population consisted of EMA-positive individuals. Although the current study did not require a positive celiac serology for the diagnosis of $\mathrm{CD}$, some $88 \%$ with available data on serology were positive at time of small intestinal biopsy [33].

To our knowledge, this is the first prospective study on smoking, moist snuff use and CD. The RRs for CD among moist snuff users were consistently around 1 , indicating that the nicotine levels of moist snuff are unlikely to protect against future $\mathrm{CD}$.

This paper has some strengths and limitations. We identified individuals with $\mathrm{CD}$ using biopsy report data from 28 Swedish pathology departments and should hence have identified an average celiac population since more than 96\% of all Swedish gastroenterologists and paediatricians biopsied their patients before CD diagnosis at the time of data collection [33].

When we validated 114 randomly selected patients using patient charts, we found that $95 \%$ of patients with villous atrophy had CD [33]. We also reviewed $>1500$ biopsy reports with villous atrophy and inflammation [33], and other diagnoses than $\mathrm{CD}$ were then very uncommon (the most common non-CD diagnosis recorded in biopsy reports with villous atrophy was IBD, seen in $0.3 \%$ of the reports) [33]. In other settings, other disorders such as autoimmune enteropathy, Whipple disease, common variable immunodeficiency, giardiasis and cow-milk protein intolerance should be considered in patients with villous atrophy [46].

A limitation of our study is that we did not screen for $\mathrm{CD}$ in our population. Considering that this study involved more than 300,000 individuals this was not feasible. Lack of serological screening might have been a problem if smoking was linked to $\mathrm{CD}$ with minor symptoms (and remaining undiagnosed) but considering that some of the lowest risk estimates for $C D(O R=0.15)$ was seen in the study by Snook et al [22] where all patients suffered from malabsorption and diarrhoea this is unlikely to be the case. In a subset of patients where we had access to patient chart data [33], some $79 \%$ of CD patients had gastrointestinal symptoms.

An additional study limitation is that we were unable to identify individuals who might have quit smoking after the first data collection. Finally, despite the large number of study participants we cannot rule out a minor inverse or positive association between $\mathrm{CD}$ and smoking due to limited study power.

Smoking influences the immune system and more specifically may decrease the intestinal permeability [47]. This could potentially protect against gliadin exposure and risk of CD, and has been argued as the cause for earlier findings of an inverse relationship between smoking 
and $\mathrm{CD}$. If smoking protects against small intestinal inflammation our data argue that substances that only occur in tobacco smoke are unlikely to explain an inverse relationship with CD since risk estimates in our study were almost identical in smokers and moist snuff users. However, the most likely explanation for RRs around 1 in both smokers and moist snuff users are that these factors do not play a major role in the aetiology of CD in a Swedish setting.

\section{Conclusions}

In conclusion, we found no association between smoking, moist snuff use and CD.

\section{Abbreviations}

CD: Celiac disease; Cl: Confidence interval; RR: Relative risk.

\section{Competing interests}

The authors (JFL, CN, and $\mathrm{BJ}$ ) declare that they have no conflicts of interest.

\section{Authors' contributions}

ICMJE criteria for authorship read and met: JFL, CN and BJ. Agree with the manuscript's results and conclusions: JFL, CN and BJ. Designed the experiments/the study: JFL and BJ. Collected data: JFL and BJ. Analyzed the data: BJ. Wrote the first draft of the paper: JFL. Contributed to the writing of the paper: $\mathrm{CN}$ and BJ. Contributed to design of study and interpretation of the data analyses: JFL, CN and BJ. Interpretation of data and approved the final version of the manuscript: JFL, CN and BJ. Responsible for data integrity: JFL and BJ. Supervised the project: JFL and BJ. Obtained funding: JFL and BJ. All authors read and approved the final manuscript.

\section{Funding}

JFL was supported by grants from the Swedish Society of Medicine, the Swedish Research Council, and the Swedish Celiac Society. CN was supported by the Swedish Society for Medical Research. BJ, was supported by grants from Swedish Research council for Health, Working Life and Welfare. None of the funders had any influence on this study. Guarantor: Jonas F Ludvigsson.

\section{Author details}

${ }^{1}$ Department of Medical Epidemiology and Biostatistics, Karolinska Institutet, Stockholm 171 77, Sweden. ${ }^{2}$ Department of Paediatrics, Örebro University Hospital, Örebro University, Örebro, Sweden. ${ }^{3}$ Department of Molecular Medicine and Surgery, Karolinska Institutet, Stockholm, Sweden. ${ }^{4}$ Department of Public Health and Clinical Medicine, Umeå University, Umeå, Sweden.

Received: 24 April 2014 Accepted: 26 June 2014

Published: 3 July 2014

\section{References}

1. Ludvigsson JF, Green PH: Clinical management of coeliac disease. J Intern Med 2011, 269(6):560-571.

2. Dube C, Rostom A, Sy R, Cranney A, Saloojee N, Garritty C, Sampson M, Zhang L, Yazdi F, Mamaladze V, Pan I, Macneil J, Mack D, Patel D, Moher D: The prevalence of celiac disease in average-risk and at-risk Western European populations: a systematic review. Gastroenterology 2005, 128(4 Suppl 1):S57-S67.

3. Walker MM, Murray JA, Ronkainen J, Aro P, Storskrubb T, D'Amato M, Lahr B, Talley NJ, Agreus L: Detection of celiac disease and lymphocytic enteropathy by parallel serology and histopathology in a population-based study. Gastroenterology 2010, 139(1):112-119.

4. Bao F, Yu L, Babu S, Wang T, Hoffenberg EJ, Rewers M, Eisenbarth GS: One third of HLA DQ2 homozygous patients with type 1 diabetes express celiac disease-associated transglutaminase autoantibodies. J Autoimmun 1999, 13(1):143-148

5. Ludvigsson JF, Olen O, Bell M, Ekbom A, Montgomery SM: Coeliac disease and risk of sepsis. Gut 2008, 57(8):1074-1080.
6. West J, Logan RF, Smith CJ, Hubbard RB, Card TR: Malignancy and mortality in people with coeliac disease: population based cohort study. BMJ 2004, 329(7468):716-719.

7. Ludvigsson JF, Montgomery SM, Ekbom A, Brandt L, Granath F: Small-intestinal histopathology and mortality risk in celiac disease. JAMA 2009, 302(11):1171-1178.

8. Hadithi M, von Blomberg BM, Crusius JB, Bloemena E, Kostense PJ, Meijer JW, Mulder CJ, Stehouwer CD, Pena AS: Accuracy of serologic tests and HLA-DQ typing for diagnosing celiac disease. Ann Intern Med 2007, 147(5):294-302.

9. Akobeng AK, Ramanan AV, Buchan I, Heller RF: Effect of breast feeding on risk of coeliac disease: a systematic review and meta-analysis of observational studies. Arch Dis Child 2006, 91(1):39-43.

10. Stene LC, Honeyman MC, Hoffenberg EJ, Haas JE, Sokol RJ, Emery L, Taki I, Norris JM, Erlich HA, Eisenbarth GS, Rewers M: Rotavirus infection frequency and risk of celiac disease autoimmunity in early childhood: a longitudinal study. Am J Gastroenterol 2006, 101(10):2333-2340.

11. Welander A, Tjernberg AR, Montgomery SM, Ludvigsson J, Ludvigsson JF: Infectious disease and risk of later celiac disease in childhood. Pediatrics 2010, 125(3):e530-e536.

12. Marild K, Stephansson O, Montgomery S, Murray JA, Ludvigsson JF: Pregnancy outcome and risk of celiac disease in offspring: a nationwide case-control study. Gastroenterology 2012, 142(1):39-45. e33.

13. Ludvigsson JF, Ludvigsson J: Stressful life events, social support and confidence in the pregnant woman and risk of coeliac disease in the offspring. Scand J Gastroenterol 2003, 38(5):516-521.

14. Ciacci C, Siniscalchi M, Bucci C, Zingone F, Morra I, lovino P: Life events and the onset of celiac disease from a patient's perspective. Nutrients 2013, 5(9):3388-3398.

15. Carlens C, Hergens MP, Grunewald J, Ekbom A, Eklund A, Hoglund CO, Askling J: Smoking, use of moist snuff, and risk of chronic inflammatory diseases. Am J Respir Crit Care Med 2010, 181(11):1217-1222.

16. Lindberg E, Tysk C, Andersson K, Jarnerot G: Smoking and inflammatory bowel disease. A case control study. Gut 1988, 29(3):352-357.

17. Harries AD, Baird A, Rhodes J: Non-smoking: a feature of ulcerative colitis. Br Med J (Clin Res Ed) 1982, 284(6317):706.

18. Mitchell SA, Thyssen M, Orchard TR, Jewell DP, Fleming KA, Chapman RW: Cigarette smoking, appendectomy, and tonsillectomy as risk factors for the development of primary sclerosing cholangitis: a case control study. Gut 2002, 51(4):567-573.

19. Vazquez H, Smecuol E, Flores D, Mazure R, Pedreira S, Niveloni S, Maurino E, Bai JC: Relation between cigarette smoking and celiac disease: evidence from a case-control study. Am J Gastroenterol 2001, 96(3):798-802.

20. Austin AS, Logan RF, Thomason K, Holmes GK: Cigarette smoking and adult coeliac disease. Scand J Gastroentero/ 2002, 37(8):978-982.

21. Todi $D$, Tsai H: Coeliac disease is associated with non-smoking and cessation of smoking. Gut 1997, 40(Suppl 1):A11.

22. Snook JA, Dwyer L, Lee-Elliott C, Khan S, Wheeler DW, Nicholas DS: Adult coeliac disease and cigarette smoking [see comments]. Gut 1996, 39(1):60-62.

23. Suman S, Williams EJ, Thomas PW, Surgenor SL, Snook JA: Is the risk of adult coeliac disease causally related to cigarette exposure? Eur J Gastroenterol Hepatol 2003, 15(9):995-1000.

24. West J, Logan RF, Hill PG, Lloyd A, Lewis S, Hubbard R, Reader R, Holmes GK, Khaw KT: Seroprevalence, correlates, and characteristics of undetected coeliac disease in England. Gut 2003, 52(7):960-965.

25. Patel AH, Loftus EV Jr, Murray JA, Harmsen WS, Zinsmeister AR, Sandborn WJ: Cigarette smoking and celiac sprue: a case-control study. Am J Gastroenterol 2001, 96(8):2388-2391.

26. Ludvigsson JF, Montgomery SM, Ekbom A: Smoking and celiac disease: a population-based cohort study. Clin Gastroenterol Hepatol 2005, 3(9):869-874.

27. Thomason K, West J, Logan RF, Coupland C, Holmes GK: Fracture experience of patients with coeliac disease: a population based survey. Gut 2003, 52(4):518-522.

28. Baba S, Wikstrom AK, Stephansson O, Cnattingius S: Influence of snuff and smoking habits in early pregnancy on risks for stillbirth and early neonatal mortality. Nicotine Tob Res 2014, 16(1):78-83.

29. Persson PG, Hellers G, Ahlbom A: Use of oral moist snuff and inflammatory bowel disease. Int J Epidemio/ 1993, 22(6):1101-1103.

30. Ludvigsson JF, Otterblad-Olausson P, Pettersson BU, Ekbom A: The Swedish personal identity number: possibilities and pitfalls in healthcare and medical research. Eur J Epidemiol 2009, 24(11):659-667. 
31. Hergens MP, Alfredsson L, Bolinder G, Lambe M, Pershagen G, Ye W: Long-term use of Swedish moist snuff and the risk of myocardial infarction amongst men. J Intern Med 2007, 262(3):351-359.

32. Purdue MP, Jarvholm B, Bergdahl IA, Hayes RB, Baris D: Occupational exposures and head and neck cancers among Swedish construction workers. Scand J Work Environ Health 2006, 32(4):270-275.

33. Ludvigsson JF, Brandt L, Montgomery SM, Granath F, Ekbom A: Validation study of villous atrophy and small intestinal inflammation in Swedish biopsy registers. BMC Gastroenterol 2009, 9(1):19.

34. Engholm G, Englund A: Morbidity and mortality patterns in Sweden. Occup Med 1995, 10(2):261-268.

35. Boffetta $P$, Jarvholm B, Brennan $P$, Nyren O: Incidence of lung cancer in a large cohort of non-smoking men from Sweden. Int I Cancer 2001, 94(4):591-593

36. Ludvigsson JF, Brandt L, Montgomery SM: Symptoms and signs in individuals with serology positive for celiac disease but normal mucosa. BMC Gastroenterol 2009, 9:57.

37. Olen O, Bihagen E, Rasmussen F, Ludvigsson JF: Socioeconomic position and education in patients with coeliac disease. Dig Liver Dis 2012, 44(6):471-476

38. Ludvigsson JF, Leffler DA, Bai JC, Biagi F, Fasano A, Green PH, Hadjivassiliou M, Kaukinen K, Kelly CP, Leonard JN, Lundin KE, Murray JA, Sanders DS, Walker MM, Zingone F, Ciacci C: The Oslo definitions for coeliac disease and related terms. Gut 2013, 62(1):43-52.

39. Snook JA, Dwyer L, Lee-Elliott C, Knan S, Wheeler DW, Nicholas DS, Merrett MN, Mortensen N, Kettlewell M, Jewell DP: Smoking benefits celiac sprue and pouchitis: implications for nicotine therapy? Gastroenterology 1997, 112(3):1048-1050.

40. Ludvigsson JF, Montgomery SM, Ekbom A: Celiac disease and risk of adverse fetal outcome: a population-based cohort study. Gastroenterology 2005, 129(2):454-463.

41. Criswell LA, Saag KG, Mikuls TR, Cerhan JR, Merlino LA, Lum RF, Pfeiffer KA, Woehl B, Seldin MF: Smoking interacts with genetic risk factors in the development of rheumatoid arthritis among older Caucasian women. Ann Rheum Dis 2006, 65(9):1163-1167.

42. Ciacci C, Cirillo M, Sollazzo R, Savino G, Sabbatini F, Mazzacca G: Gender and clinical presentation in adult celiac disease. Scand J Gastroenterol 1995, 30(11):1077-1081.

43. Rampertab SD, Pooran N, Brar P, Singh P, Green PH: Trends in the presentation of celiac disease. Am J Med 2006, 119(4):355. e359-314.

44. Ludvigsson JF, Rubio-Tapia A, van Dyke CT, Melton $L$ 3rd, Zinsmeister AR, Lahr BD, Murray JA: Increasing incidence of celiac disease in a north american population. Am J Gastroenterol 2013, 108(5):818-824.

45. Prasad S, Thomas P, Nicholas DS, Sharer NM, Snook JA: Adult endomysial antibody-negative coeliac disease and cigarette smoking. Eur $J$ Gastroenterol Hepatol 2001, 13(6):667-671.

46. Dickson BC, Streutker CJ, Chetty R: Coeliac disease: an update for pathologists. J Clin Pathol 2006, 59(10):1008-1016.

47. McGilligan VE, Wallace JM, Heavey PM, Ridley DL, Rowland IR: Hypothesis about mechanisms through which nicotine might exert its effect on the interdependence of inflammation and gut barrier function in ulcerative colitis. Inflamm Bowel Dis 2007, 13(1):108-115.

doi:10.1186/1471-230X-14-120

Cite this article as: Ludvigsson et al: Smoking, use of moist snuff and risk of celiac disease: a prospective study. BMC Gastroenterology 2014 14:120

\section{Submit your next manuscript to BioMed Central and take full advantage of:}

- Convenient online submission

- Thorough peer review

- No space constraints or color figure charges

- Immediate publication on acceptance

- Inclusion in PubMed, CAS, Scopus and Google Scholar

- Research which is freely available for redistribution 